\title{
Imaging surface plasmon resonance for multiplex microassay sensing of mycotoxins
}

\author{
Denis Dorokhin • Willem Haasnoot • \\ Maurice C. R. Franssen • Han Zuilhof • \\ Michel W. F. Nielen
}

Received: 14 February 2011 /Revised: 28 March 2011 /Accepted: 29 March 2011 /Published online: 12 April 2011

(C) Springer-Verlag 2011

\begin{abstract}
A prototype imaging surface plasmon resonancebased multiplex microimmunoassay for mycotoxins is described. A microarray of mycotoxin-protein conjugates was fabricated using a continuous flow microspotter device. A competitive inhibition immunoassay format was developed for the simultaneous detection of deoxynivalenol (DON) and zearalenone (ZEN), using a single sensor chip. Initial in-house validation showed limits of detection of 21 and $17 \mathrm{ng} / \mathrm{mL}$ for DON and 16 and $10 \mathrm{ng} / \mathrm{mL}$ for ZEN in extracts, which corresponds to 84 and $68 \mu \mathrm{g} / \mathrm{kg}$ for DON and 64 and $40 \mu \mathrm{g} / \mathrm{kg}$ for ZEN in maize and wheat samples, respectively. Finally, the results were critically compared with data obtained from liquid chromatography-mass spectrometry confirmatory analysis method and found to be in good agreement. The described multiplex immunoassay for the rapid screening of several mycotoxins meets European Union regulatory limits and represents a robust platform for mycotoxin analysis in food and feed samples.
\end{abstract}

Keywords Imaging surface plasmon resonance $\cdot$ Multiplex immunoassay · Mycotoxins · Deoxynivalenol $\cdot$ Zearalenone

D. Dorokhin • M. C. R. Franssen • H. Zuilhof • M. W. F. Nielen Laboratory of Organic Chemistry, Wageningen University, Dreijenplein 8,

6703 HB Wageningen, The Netherlands

W. Haasnoot $\cdot$ M. W. F. Nielen $(\square)$

RIKILT-Institute of Food Safety,

Wageningen UR, P.O. Box 230,

6700 AE Wageningen, The Netherlands

e-mail: michel.nielen@wur.nl

\section{Introduction}

Mycotoxins, secondary metabolites of fungi, are commonly found in food and feed commodities as well as in agricultural crops. Mycotoxin species were found as metabolic products of various groups of fungi, e.g., Aspergillus, Fusarium, Penicillium, etc. [1]. These secondary metabolites are poisonous for humans and animals. Mycotoxins play substantial roles in spoilage of food, beverages, and feed for livestock [2]. The occurrence of mycotoxins in food and feed products might have serious impact on economy. The regulations of maximum mycotoxin levels in food and animal feed have been established in many countries including European Union (EU) members [3].

Several analytical techniques have been reported and are widely used in order to detect the presence of mycotoxin contaminants [4-7]. The most common (conventional) confirmatory method for the detection of mycotoxins in food and feed samples is high-pressure liquid chromatography or gas chromatography in combination with UV-VIS spectroscopy or/and mass spectrometry [8-13]. These methods allow simultaneous analysis of several toxins; however, they require laboratory facilities, qualified personnel, as well as extensive cleanup procedures for sample preparation. Another group of detection techniques include rapid screening assays based on an immunoreaction between antibodies and antigens such as enzyme-linked immunosorbent assays (ELISAs) [14-18], lateral flow devices (LFDs) [19, 20], fluorescence polarization immunoassays (FPIA) [21-23], an optical waveguide biosensor [24], and a multiplex flow cytometric immunoassay (FCIA) [25]. Recently, two technically new approaches were found for mycotoxin detection utilizing an acoustic principle of 
sensing [26] and Raman spectroscopy [27]. However, this multitude of approaches has not led to a routinely and generally applicable approach. ELISA tests are well-known but have numerous disadvantages, such as a long assay development time and non-recoverable consumables. Simple LFD immunoassays are capable of providing mainly qualitative results without precise quantification of data. FPIA and FCIA assays are solution-based methods that require labeling in contrast with optical biosensor immunoassays. Finally, the developed array biosensor based on the optical waveguide technology requires a time-consuming fabrication procedure and is limited by the number of channels for toxin detection [24].

Eventually, surface plasmon resonance (SPR) has attracted attention as a fast label-free screening method for the detection of food contaminants, in particular, mycotoxins [28-34]. This technique has a number of advantages: SPR is a rapid label-free detection method that gives quantitative and qualitative information of the analyzed samples and provides the possibility to reuse the sensor chip for many analytical cycles [35]. Performing SPR in an imaging format (iSPR) allows multiplex screening of tens of different biointeractions using a microarray of sensing spots [36, 37]. So far, the maximum number of mycotoxins detected using a conventional SPR sensor chip is limited to four [30].

In this article, we report on the application of a multiplex microassay platform, and we developed a rapid screening of DON and zearalenone (ZEN) in feed commodities, which is also applicable to related mycotoxins. The detection principle is based on iSPR, which allows analysis for several toxins with a single multiplexed microassay sensor chip. The fabricated microassays were tested for cross-reactivity with other mycotoxins that often occur in food and feed products. The developed microassay was in-house validated for screening of mycotoxin-contaminated wheat and maize extracts. The obtained data were critically compared with a confirmatory liquid chromatography-mass spectrometry (LC-MS/MS) method.

\section{Materials and methods}

Chemical and reagents Mycotoxin standards, e.g., DON, deoxynivalenol-3-glucoside (DON3G), 3-acetyldeoxynivalenol (3-AcDON), 15-acetyl-deoxynivalenol (15-AcDON), T-2 toxin, HT-2, nivalenol (NIV), ZEN, alfazearalenol $\left(\alpha\right.$-ZEL), beta-zearalenol ( $\beta$-ZEL), aflatoxins $B_{1}$, $\mathrm{B}_{2}, \mathrm{G}_{1}, \mathrm{G}_{2}$ (AFB1, AFB2, AFG1, AFG2), fumonisin $\mathrm{B}_{1}, \mathrm{~B}_{2}$, $\mathrm{B}_{3}$, (FB1, FB2, FB3), and ochratoxin A (OTA) were purchased from Biopure Referenzsubstanzen $\mathrm{GmbH}$ (Tulln, Austria). The mycotoxin standard zearalenone sulfate (ZENS) was kindly provided by the Van ' $t$ Hoff Institute for Molecular
Sciences of the University of Amsterdam (Amsterdam, The Netherlands). The iSPR rectangular sensor chips Easy2spot coated with pre-activated carboxylated dextran hydrogel were supplied by IBIS Technologies (Enschede, The Netherlands). The running HBS-EP buffer (containing $10 \mathrm{mM}$ 4-(2-hydroxyethyl)piperazine-1-ethanesulfonic acid $\mathrm{pH} 7.4,150 \mathrm{mM}$ sodium chloride, $3 \mathrm{mM}$ EDTA, and $0.005 \%(v / v)$ surfactant polysorbate (P20)), $1 \mathrm{M}$ ethanolamine hydrochloride $\mathrm{pH} 8.5$, and $10 \mathrm{mM}$ acetate buffers (pH 3.5 and 4.5) were received from GE Healthcare (Uppsala, Sweden). DON and ZEN ovalbumin conjugates (DON-OVA and ZEN-OVA) and monoclonal antibodies (Mabs) against deoxynivalenol $(\mathrm{aDON})$ and zearalenone (aZEN) were purchased from Aokin $A G$ (Berlin, Germany). Neutral liquid detergent RBS T230 was purchased from R. Borghgraef S.A. (Brussels, Belgium). Ovalbumin (OVA), sodium acetate, Tween 20, and anhydrous dimethyl sulfoxide were purchased from Sigma-Aldrich (Zwijndrecht, The Netherlands).

Microarray fabrication The toxin-protein conjugates DON-OVA and ZEN-OVA and unconjugated OVA were diluted in $10 \mathrm{mM}$ sodium acetate buffer of different $\mathrm{pH}$ $(3.5,4,4.5$, and 5$)$ until a final concentration of $50 \mu \mathrm{g} / \mathrm{mL}$. The $\mathrm{pH}$ scouting for optimum covalent binding of the protein conjugates to the carboxylated surface of the sensor chip was performed in a Biacore 3000 (GE Healthcare, Uppsala, Sweden) SPR instrument using a $\mathrm{pH}$ scouting wizard. The optimum $\mathrm{pH}$ of 3.5 was used for the mycotoxinOVA conjugates, and they were spotted on the pre-activated carboxylated polymeric hydrogel chip surface during $1 \mathrm{~h}$ using a continuous flow microspotter (CFM; Wasatch Microfluidics, USA). Ovalbumin was immobilized from $10 \mathrm{mM}$ sodium acetate buffer at $\mathrm{pH}$ 4.5. Subsequently, the chip surface was blocked with ethanolamine for $10 \mathrm{~min}$ and rinsed with HBS-EP buffer and MilliQ water. In order to determine the optimal concentration, toxin-protein conjugates were immobilized at different concentrations (DON-OVA at 200, $100,50,25,12.5 \mu \mathrm{g} / \mathrm{mL}$; ZEN-OVA at 10, 5, 2.5, 1.25, $0.6253 \mu \mathrm{g} / \mathrm{mL}$; OVA at $10,5,2.5,1.25,0.625 \mu \mathrm{g} / \mathrm{mL}$ ).

iSPR measurements iSPR was carried out using the IBIS iSPR instrument (IBIS Technologies, Enschede, The Netherlands). The rectangular sensor chip containing the mycotoxins microarray was placed into the chip holder with the hemisphere prism, and a microfluidic cell was installed on top. Two syringe pumps were used either to deliver the sample solution to the chip surface or to flush/ flow the analyte solution backward and forward at $20 \mu \mathrm{L} / \mathrm{s}$ over the sensor surface. The SPR angle shifts were measured for every microarray spot (region of interests (ROI)). For data analysis, Sprint software was used (IBIS Technologies). Sensorgrams were recorded during the 
injection of a mixture of $40 \mu \mathrm{L}$ of the monoclonal antibodies (aDON $20 \mu \mathrm{g} / \mathrm{mL}$ and aZEN $5 \mu \mathrm{g} / \mathrm{mL}$ ) and $40 \mu \mathrm{L}$ of the multianalyte standard solution containing DON and ZEN toxins (0, 0.1, 1, 2.5, 5, 10, 25, 50, 100, $1,000 \mathrm{ng} / \mathrm{mL})$. The injection volume into the microfluidic cell was $80 \mu \mathrm{L}$. All toxin and antibody solutions were diluted in HBS-EP buffer. To remove the bound Mabs and to prepare the sensor chip for the next analytical cycle, the chip surface was regenerated by the injection of $10 \mathrm{mM}$ $\mathrm{HCl}$ for $30 \mathrm{~s}$. The entire iSPR cycletime was approximately $14 \mathrm{~min}$. The recorded sensorgrams were zeroed to the baseline of the buffer signal before the injection of the Mabs. For each mycotoxin spot, the maximum response was calculated from the data points recorded during the dissociation step. The sensorgrams were recorded at a constant temperature of $25^{\circ} \mathrm{C}$.

Standard calibration curves and LOD The calibration curves were plotted from the calculated values of the relative binding $\left(B / B_{0}\right)$, where $B$ is the response of the solution containing toxin plus antibodies and $B_{0}$ is the response of the blank solution containing antibodies, versus concentration of the toxin in the standard solution or sample matrix extract, respectively. The calibration curves were fitted with a non-linear four-parameter model using GraphPad Prism software (GraphPad Software Inc., USA). From the calibration curves, the half maximal inhibitory concentration $\left(\mathrm{IC}_{50}\right)$ was calculated. In addition, limits of detection (LODs) were estimated by analyzing blank samples six times and subtracting three times the standard deviation (3SD) from the average of the relative responses.

Specificity of the microassay The specificity of the microassay was tested against commonly occurring mycotoxins and masked toxins having similar chemical structures (DON3G, 3-AcDON, 15-AcDON, NIV, T2, HT2, $\alpha$-ZEL, $\beta$-ZEL, AFB1, AFB2, AFG1, AFG2, FB1, FB2, FB3, OTA, and ZENS). The $\mathrm{IC}_{50}$ values were calculated from calibration curves, and the cross-reactivity was assessed with respect to DON and ZEN, respectively.

Preparation of wheat and maize extracts Samples of $2.5 \mathrm{~g}$ were milled and extracted with $10 \mathrm{~mL}$ of acetonitrilewater-formic acid (84:16:1). Of this extraction solvent, $100 \mu \mathrm{L}$ was evaporated under a flow of nitrogen. In the case of spiked blank extracts, DON and ZEN were spiked at different concentrations $(0.1-1,000 \mathrm{ng} / \mathrm{mL})$. After evaporation, the residue in the vial was dissolved in $100 \mu \mathrm{L}$ of HBS-EP buffer containing $10 \%$ of DMSO. The solution was centrifuged at $11,000 \mathrm{rpm}$ for $10 \mathrm{~min}$. Subsequently, $100 \mu \mathrm{L}$ of the supernatant was collected for iSPR measurements. The entire preparation procedure for several samples in parallel can be performed within $1 \mathrm{~h}$.
Liquid chromatography tandem mass spectrometry The LC-MS/MS system consisted of a Shimadzu (Kyoto, Japan) LC system equipped with an ABI Sciex (Foster City, USA) model QTRAP 5500 triple quadrupole mass spectrometer. For DON and 3- and 15-AcDON, the mass spectrometer was operated in the positive electrospray ionization mode at a capillary voltage of $5.0 \mathrm{kV}$, a desolvation temperature of $400{ }^{\circ} \mathrm{C}$, and an entrance voltage of $10 \mathrm{~V}$. Desolvation gas was nitrogen, and the CID gas was argon. ZEN, $\alpha-Z E L$, and $\beta$-ZEL were ionized in the negative mode at $-4.0 \mathrm{kV}$. Data were acquired in the multiple reaction monitoring mode using the following ion transitions: DON $[\mathrm{M}+\mathrm{H}]^{+}$ $m / z 297 \rightarrow 231$ and $m / z 297 \rightarrow 249$, AcDON $\left[\mathrm{M}+\mathrm{NH}_{4}\right]^{+} m / z$ $356 \rightarrow 137$ and $m / z \quad 356 \rightarrow 321 ; \mathrm{ZEN}[\mathrm{M}-\mathrm{H}]^{-} \mathrm{m} / z \quad 317 \rightarrow 175$ and $m / z \quad 317 \rightarrow 131$, ZEL $[\mathrm{M}-\mathrm{H}]^{-} \mathrm{m} / z \quad 319 \rightarrow 160$ and $m / z$ $319 \rightarrow 130$. The analytical column was a $100 \times 2.1 \mathrm{~mm}$ i.d. $3 \mu \mathrm{m}$ Ultra Aqueous C18 (Restek, Bellefonte, PA, USA) column, kept in a column oven at $35{ }^{\circ} \mathrm{C}$. The two mobile phases used consisted of (A) water/formic acid/1 M ammonium formate (100:1:0.1) and (B) methanol/water/ formic acid/1 $\mathrm{M}$ ammonium formate (95:5:1:0.1), and the flow was $0.4 \mathrm{~mL} / \mathrm{min}$. Following a 1 -min isocratic period at $0 \% \mathrm{~B}$, a linear gradient was started towards $50 \% \mathrm{~B}$ at $2 \mathrm{~min}$, isocratic until $3 \mathrm{~min}$, then followed by a gradient towards $100 \% \mathrm{~B}$ at $8 \mathrm{~min}$, and then kept at that composition until $10 \mathrm{~min}$. The injection volume was $10 \mu \mathrm{L}$.

The concentrations of the mycotoxins were calculated using the standard addition method following the addition of $500 \mu \mathrm{g} / \mathrm{kg}$ DON and $50 \mu \mathrm{g} / \mathrm{kg} \mathrm{ZEN} \mathrm{to} \mathrm{a} \mathrm{second} \mathrm{portion}$ of the sample.

\section{Results and discussion}

Development of the microarray sensor chip Different detection formats can be applied for designing an SPR immunoassay [35]. The competitive inhibition format is found to be the most suitable and robust format for the detection of small organic molecules like mycotoxins. Direct immobilization of mycotoxin-protein conjugates (DON ovalbumin and ZEN ovalbumin) on chip surface results in a robust and stable microassay in comparison with immobilized antibodies, which are susceptible to denaturation and proteolytic degradation [38]. In the inhibition format, during the injection over the sensor chip, the antibodies are mixed with the mycotoxins in solution. The higher the mycotoxin concentration in the solution, the lower is the binding of the antibodies to the mycotoxinprotein conjugates immobilized on the chip surface.

A CFM was used in order to fabricate the microarray sensor chip. In contrast to contact spotting, this instrument yields a microarray with uniform morphology on the spot without crosstalk [39]. The commercially available DON- 
OVA and ZEN-OVA toxin-protein conjugates were covalently attached to the surface and coupled via the amine groups of the OVA to the gold substrate coated with preactivated carboxylated polymeric hydrogel. Such a coupling is expected to provide a stable array with covalently attached toxin-protein conjugates on the surface [29, 30].

Figure 1a shows a sensor chip image of different concentrations of the two mycotoxin-OVA conjugates and OVA successfully spotted on the surface of the sensor chip. OVA was immobilized as reference spots in order to control the mycotoxin-specific binding of the DON and ZEN Mabs. The microarray image demonstrates uniform morphology as well as precise separation between spots. The concentration needed for immobilization of ZEN-OVA conjugate is ten times lower than that for the DON-OVA conjugate, based on the response of the Mab binding. The toxin-protein conjugates were easy to spot from the buffer having a lower $\mathrm{pH}$ of 3.5 .

Next, SPR sensorgrams were measured from four different predefined ROIs during the injection of the mixture of the two antibodies, in order to test the performances of the binding and cross-interaction to the immobilized mycotoxins on the fabricated microarray (Fig. 1b). The sensorgrams begin with the baseline, followed by the association step, where the injection of the antibodies mixture results in rising of the responses due to the specific interactions of the antibodies in the solution to the mycotoxin pattern on the chip surface. Subsequently, buffer is injected for the dissociation step. The difference in responses of the defined ROIs of mycotoxin and reference spots (unmodified sensor chip surface) gives quantitative information of the specifically bound antibodies.
In order to remove bound antibodies and to prepare the sensor chip for the next measurement cycle, an efficient regeneration step is vital. Incomplete regeneration or the loss of the capturing molecules from the chip surface will decrease the performance of the microarray. Depending on the capturing molecule and analyte, various regeneration solutions can be applied. The higher the multiplexity of the chip is the more complex will be the optimization of the regeneration phase. For the DON and ZEN multiplex microarray, the most suitable regeneration solution was a short pulse injection $(30 \mathrm{~s})$ of $10 \mathrm{mM} \mathrm{HCl}$.

Cross-reactivity profile The fabricated microassay was tested with other mycotoxins which often occur in food and feed products. The DON and ZEN Mabs did not show interactions with the following mycotoxins: T-2, HT-2, NIV, AFB1, AFB2, AFG1, AFG2, FB1, FB2, FB3, OTA, and ZENS in a high concentration (1 $\mu \mathrm{g} / \mathrm{mL}$ in buffer). However, the DON Mab demonstrated cross-reactivity with the conjugated (masked) forms of DON (Table 1). The ZEN Mab showed a high cross-reactivity towards $\alpha$-ZEL (54\%) and $\beta$-ZEL (137\%; Table 1).

The cross-reactivity of the Mabs might lead to some overestimation of mycotoxin concentration in the sample; however, for a rapid multiplex screening assay, this is not necessarily an obstacle. The presence of masked forms of parental DON and ZEN deserves attention during quantitative analysis using the immunoassay biosensors. The cross-reactivity of the DON and ZEN Mabs for the conjugated forms have been reported in several studies [14-16, 18, 33, 34, 40-42]. We have also observed high cross-reactivity of DON Mabs with acetylated forms of DON as well as ZEN Mabs with $\alpha$ - and $\beta$-ZEL masked a)

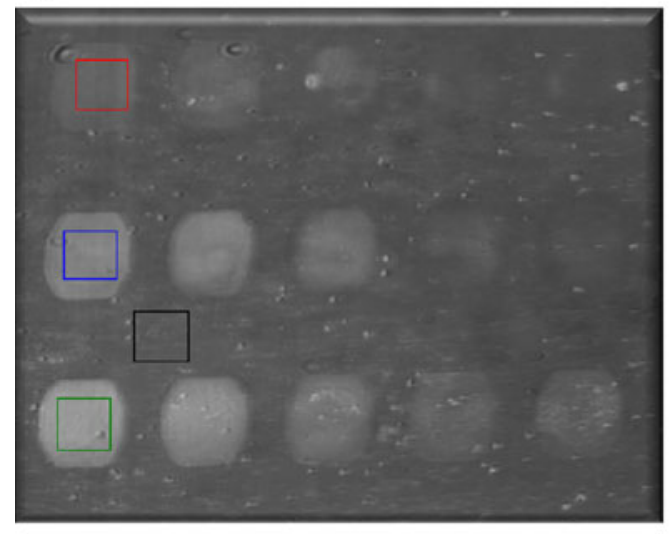

b)

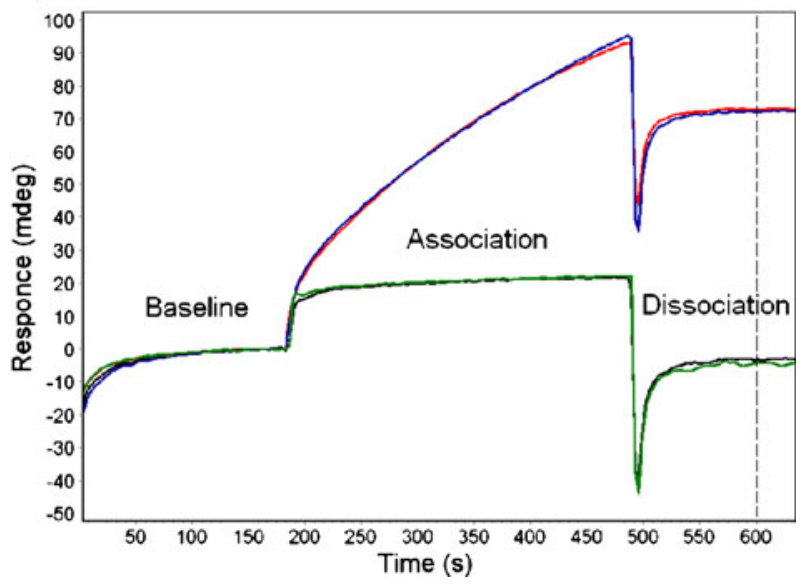

$600 \mu \mathrm{m}$. b SPR sensorgrams recorded on DON (red), ZEN (blue), OVA (green), and blank (black) ROIs during the injection of DON and ZEN antibodies mixture in the buffer solution. The dashed line indicates the response difference used for calculations 
Table 1 Cross-reactivity (CR) of DON and ZEN antibodies with other mycotoxins calculated from $\mathrm{IC}_{50}$ values as a percentage relative to DON or ZEN, respectively

\begin{tabular}{|c|c|c|}
\hline \multirow[t]{2}{*}{ Toxin } & \multicolumn{2}{|c|}{ Cross-reactivity, $\%$} \\
\hline & $\mathrm{aDON}$ & aZEN \\
\hline DON & 100 & 0 \\
\hline 3-AcDON & 71 & 0 \\
\hline 15-AcDON & 66 & 0 \\
\hline DON3G & 36 & 0 \\
\hline ZEN & 0 & 100 \\
\hline$\alpha-Z E L$ & 0 & 59 \\
\hline$\beta-Z E L$ & 0 & 137 \\
\hline ZENS & 0 & 0 \\
\hline $\mathrm{T}-2$ & 0 & 0 \\
\hline HT-2 & 0 & 0 \\
\hline NIV & 0 & 0 \\
\hline AFB1 & 0 & 0 \\
\hline AFB2 & 0 & 0 \\
\hline AFG1 & 0 & 0 \\
\hline AFG2 & 0 & 0 \\
\hline FB1 & 0 & 0 \\
\hline FB2 & 0 & 0 \\
\hline FB3 & 0 & 0 \\
\hline OTA & 0 & 0 \\
\hline
\end{tabular}

mycotoxins. However, there are commercially available test kits demonstrating low cross-reactivity profile towards masked mycotoxins [40, 42]. Remarkably, ZEN antibodies did not show any cross-reactivity towards the sulfate conjugate (ZENS). The specificity and binding strengths of antibodies strongly depends on the method of antibody production [17, 33, 41], and detailed choice of antibodies will thus influence the performance (specificity and sensitivity) of an immunoassay.

Initial in-house validation For critical evaluation of the sensitivity of the multiplex assay, calibration curves were constructed from sensorgrams recorded for the mixture of DON and ZEN standards in buffer with known concentrations $(0-1000 \mathrm{ng} / \mathrm{mL})$. From the calibration curves depicted in Fig. 2, the half-maximum inhibitory values $\left(\mathrm{IC}_{50}\right)$ were calculated to be 35 and $10 \mathrm{ng} / \mathrm{mL}$ for DON and ZEN, respectively. The goodness and steepness of the curves show that the 4P model is the appropriate fitting model for the obtained data (Table 2). The LODs were calculated to be $9 \mathrm{ng} / \mathrm{mL}$ for DON and $4 \mathrm{ng} / \mathrm{mL}$ for ZEN. Comparatively to SPR immunoassays developed previously, the assay shows $\sim 2-3$ times lower sensitivity $[29,30,34]$. Unfortunately, not all references provide comprehensive data allowing comparison of the developed assay [30]. The performance of the assay can be improved by selecting Mab clones having higher sensitivity as discussed above or by the dilution of extracts in order to decrease matrix effect $[29,30,33]$. Furthermore, a hardware upgrade will increase the sensitivity of the instrument. Next, the microassay was tested for the analysis of wheat and maize extracts spiked with DON and ZEN. Figure 2 shows that the calibration curves shift for matrix-derived products to the right, indicating a small decrease of the microassay sensitivity with respect to the results obtained in buffer. Decrease in the sensitivity is attributed to the influence of matrix components on the antibody binding in the solution and/or on the chip surface. The matrix effect on the performance of the immunoassay has been observed previously in sample extracts $[33,36]$.

Table 2 shows the $4 \mathrm{P}$ model fitting data for curves in sample extracts. The goodness of the curves demonstrates that $4 \mathrm{P}$ model also fits the maize- and wheat-derived data well. The steepness of curves did not change remarkably

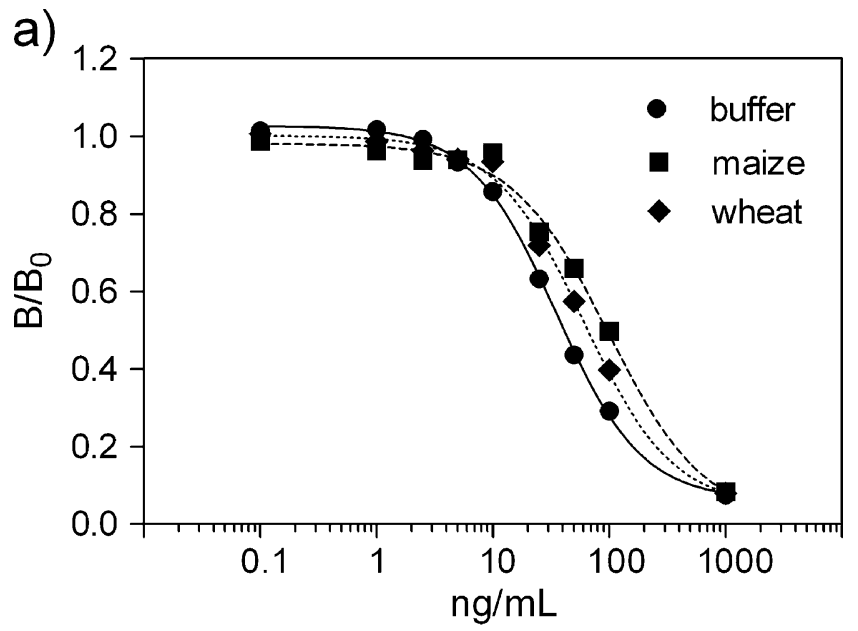

b)

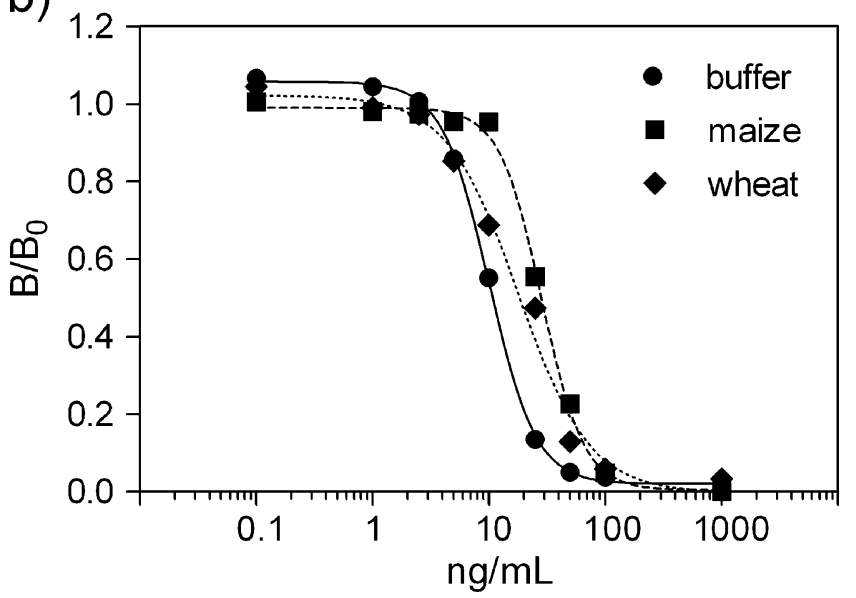

Fig. 2 Calibration curves for the multimycotoxin standard solution in buffer and in spiked extracts from maize and wheat samples calculated from the iSPR sensorgrams (DON (a), ZEN (b)). Solid, dashed, and dotted lines show 4P model fitting 
Table 2 Sensitivity of multiplex microassay and fitting parameters

${ }^{\text {a }}$ Goodness of the four-parameter model fit to the calibration curve

${ }^{\mathrm{b}} \mathrm{IC}_{50}$ value derived from the fourparameter model fit of the calibration curve

\begin{tabular}{lccll}
\hline Toxin & Goodness of $4 \mathrm{P} \mathrm{fit}^{\mathrm{a}}, R^{2}$ & Curve steepness $(\mathrm{mL} / \mathrm{ng})$ & $\mathrm{IC}_{50}(\mathrm{ng} / \mathrm{mL})^{\mathrm{b}}$ & $\mathrm{LOD}(\mathrm{ng} / \mathrm{mL})$ \\
\hline DON (buffer) & 0.9994 & -1.181 & 35 & 9 \\
DON (maize) & 0.9966 & -1.138 & 113 & 21 \\
DON (wheat) & 0.9922 & -1.048 & 62 & 17 \\
ZEN (buffer) & 0.9997 & -2.154 & 10 & 4 \\
ZEN (maize) & 0.9900 & -1.410 & 29 & 16 \\
ZEN (wheat) & 0.9979 & -2.392 & 19 & 10 \\
\hline
\end{tabular}

except the curve for ZEN-containing wheat extract. Subsequently, we have calculated LOD values for the mycotoxins in maize and wheat extracts. The results for DON and ZEN are 21 and $17 \mathrm{ng} / \mathrm{mL}$ in maize extracts and 16 and $10 \mathrm{ng} / \mathrm{mL}$ in wheat extracts, respectively. Evidently, due to matrix effects, these values show a decrease in sensitivity depending on the matrix and toxin. In practice, we recommend using a calibration sample prepared in a blank matrix. The LOD values calculated for the analysis of maize and wheat samples correspond to 84 and $68 \mu \mathrm{g} / \mathrm{kg}$ for DON and 64 and $40 \mu \mathrm{g} / \mathrm{kg}$ for ZEN. These are adequate with respect to the EU legislation limits established for DON in unprocessed durum wheat, maize, and oats $(1750 \mu \mathrm{g} / \mathrm{kg})$; unprocessed cereals $(1250 \mu \mathrm{g} / \mathrm{kg})$; breakfast cereal $(500 \mu \mathrm{g} / \mathrm{kg})$, and baby food $(200 \mu \mathrm{g} / \mathrm{kg})$. The EU legislation limits for ZEN are the following: in unprocessed maize, $200 \mu \mathrm{g} / \mathrm{kg}$; unprocessed cereals other than maize, $100 \mu \mathrm{g} / \mathrm{kg}$; cereals intended for direct human consumption, $75 \mu \mathrm{g} / \mathrm{kg}$ [3]. Note that we did not apply any extra cleanup procedure prior to injection in contrast to previously reported methods.

Recently, various optical biosensors based on the SPR sensing principle were developed for the detection of mycotoxins. Nevertheless, most of them do not offer the possibility of multiplexing for the rapid screening of several toxins on one sensor chip [28-30, 33, 34]. The developed iSPR assay on the other hand can be upgraded for measurement up to 40 different toxins and does not require extensive sample preparation (incubation, dilution) or cleanup procedures [28, $29,33]$. The sensitivity range of the developed assay is in good agreement with the results reported previously for the SPR sensing of mycotoxins [29, 30, 33, 34].

Application to real samples The developed multiplex sensor chip has been tested for the analysis of naturally contaminated samples. The values obtained from the recorded sensorgrams were fitted into calibration curves determined in maize and wheat extracts. The estimated concentrations for DON and ZEN mycotoxins are summarized in Table 3.

The iSPR data thus obtained were essentially compared with the data from an accredited confirmatory LC-MS/MS method. The obtained data show that our method yields comparable results. However, the SPR assay demonstrated slightly lower levels of mycotoxins in extracts compared with the confirmatory LC-MS/MS method. To perform more accurate measurements, a protocol for the sample preparation should be developed and established depending on the matrix nature [33]. In combination with such protocol, the currently described approach thus offers the potential for rapid and accurate multianalyte analysis of mycotoxins in food.

\section{Conclusions}

The multiplex microarray immunosensor based on the iSPR sensing principle allows for the qualitative and quantitative simultaneous and label-free detection of several mycotoxins in multianalyte sample extracts with sensitivities of 84 and $68 \mu \mathrm{g} / \mathrm{kg}$ for DON and 64 and $40 \mu \mathrm{g} / \mathrm{kg}$ for $\mathrm{ZEN}$ in maize and wheat samples, respectively. The developed multiplex immunoassay is suitable for rapid screening of maize and wheat extract without a complex and time-consuming sample preparation procedure. Despite a small sample matrix effect, the sensitivity of the assay falls well into EU regulatory limits. The results obtained using a single sensor chip are in good agreement with LC-MS/MS data. The iSPR sensor chip platform has perspective for the development of a rapid multiplex screening method for up to 40 different mycotoxins.
Table 3 Toxin concentrations in maize and wheat extracts measured by iSPR and LC-MS/MS

${ }^{\text {a }}$ Spiked maize/wheat extracts

\begin{tabular}{|c|c|c|c|c|}
\hline \multirow[t]{2}{*}{ Sample } & \multicolumn{2}{|l|}{ iSPR } & \multicolumn{2}{|l|}{ LC-MS/MS } \\
\hline & $\mathrm{DON}(\mathrm{ng} / \mathrm{mL})$ & $\mathrm{ZEN}(\mathrm{ng} / \mathrm{mL})$ & $\mathrm{DON}(\mathrm{ng} / \mathrm{mL})$ & $\mathrm{ZEN}(\mathrm{ng} / \mathrm{mL})$ \\
\hline Maize & $<\mathrm{LOD}$ & - & 20 & - \\
\hline Wheat & - & - & - & - \\
\hline Maize $^{\mathrm{a}}$ & 253 & $<\mathrm{LOD}$ & 270 & 12.5 \\
\hline Wheat $^{\mathrm{a}}$ & 218 & - & 250 & 12.5 \\
\hline
\end{tabular}


Acknowledgments The authors thank Mr. Ed Boers (RIKILT) for providing wheat and maize extracts and the LC-MS/MS data. Dr. Alex van der Kooi and Dr. Richard Schasfoort (IBIS Technologies) are acknowledged for fruitful discussions. The Nano4Vitality program of the provinces Gelderland and Overijssel is highly appreciated for financial support.

\section{References}

1. Betina V (1989) Mycotoxins chemical, biological and environmental aspects Elsevier Amsterdam-Oxford-New York-Tokyo 1939 192-237

2. Bennett JW, Klich M (2003) Clin Microbiol Rev 16:497-516

3. Commission Regulation EC No 1881 (2006) Off J Eur Union L 364:5-24

4. Krska R, Molinelli A (2007) Anal Bioanal Chem 387:145-148

5. Krska R, Welzig E, Berthiller F, Molinelli A, Mizaikoff B (2005) Food Addit Contam 22:345-353

6. Krska R, Schubert-Ullrich P, Molinelli A, Sulyok M, McDonald S, Crews C (2008) Food Addit Contam 25:152-163

7. Cigic IK, Procen H (2009) Int J Mol Sci 10:65-115

8. Cahill LM, Kruger SC, McAlice BT, Ramsey CS, Prioli R, Kohn B (1999) J Chromatogr A 859:23-28

9. Tanaka T, Yoneda A, Inoue S, Sugiura Y, Ueno Y (2000) J Chromatogr A 882:23-28

10. Schothorst RC, Jeker AA (2001) Food Chem 73:111-117

11. Berthiller F, Schuhmacher R, Buttinger G, Krska R (2005) J Chromatogr A 1062:209-216

12. Pussemier L, Pierard JY, Anselme M, Tangni EK, Motte JC, Larondelle Y (2006) Food Addit Contam 23:1208-1218

13. Vendl O, Berthiller F, Crews C, Krska R (2009) Anal Bioanal Chem 395:1347-1354

14. Sinha RC, Savard ME, Lau R (1995) J Agric Food Chem 43:1740-1744

15. Casale WL, Pestka J, Hart LP (1998) J Agric Food Chem 36:663668

16. Maragos CM, McCormick SP (2000) Food Agric Immunol 12:181-192

17. Schneider L, Pichler H, Krska RJ (2000) Anal Chem 367:98-100

18. Yoshizava T, Kohno H, Ikeda K, Shinoda T, Yokohama H, Morita K, Kusada O, Kobayashi Y (2004) Biosci Biotechnol Biochem 68:2076-2085

19. Kolosova AY, Sibanda L, Dumolin F, Lewis J, Duveiller E, Van Peteghem C, De Saeger S (2008) Anal Chim Acta 616:235-244
20. Goryacheva IY, Rusanova TY, Burmistrova NA, De Saeger S (2009) J Anal Chem 10:768-785

21. Maragon CM, Plattner RD (2002) J Agric Food Chem 50:18271832

22. Lippolis V, Pascale M, Visconti A (2006) J Food Prot 11:27122719

23. Lattanzio VMT, Pascale M, Visconti A (2009) Trends Anal Chem 28:758-768

24. Ngundi MM, Qadri SA, Wallace EV, Moore MH, Lassman ME, Shriver-Lake LC, Ligler FS, Taitt CR (2006) Environ Sci Technol 40:2352-2356

25. Peters J, Bienenmann-Ploum M, de Rijk T, Haasnoot W (2011) Mycotoxin Research doi:10.1007/s12550-010-0077-0

26. Juodeikine G, Basinskiene L, Vidmantiene D, Bartkeine E, Kunigelis V, De Koe WJ (2008) World Mycotoxins J 1:267-274

27. Liu Y, Delwiche SR, Dong Y (2009) Food Addit Contam 26:1396-1401

28. Schnerr H, Vogel RF, Niessen L (2002) Food Agric Immunol $14: 113-321$

29. Tudos AJ, van der Bos Lucas ER, Stigter ECA (2003) J Agric Food Chem 51:5843-5848

30. Van de Graag B, Spath S, Dietrich H, Stigter ECA (2003) Food Control 51:251-254

31. Hodnik V, Anderluh G (2009) Sensors 9:1339-1354

32. Meneely JP, Sulyok M, Baumgartner S, Krska R, Elliott CT (2010) Talanta 81:630-636

33. Meneely JP, Fodey T, Armstrong L, Sulyok M, Krska R, Elliott CT (2010) J Agric Food Chem 58:8936-8941

34. Kadota T, Takezawa Y, Hirano S, Tajima O, Maragos CM, Nakajima T, Tanaka T, Kamata Y, Sugita-Konishi Y (2010) Anal Chim Acta 673:173-178

35. Homola J (2008) Chem Rev 108:462-493

36. Rebe Raz S, Bremer MGEG, Giesbers M, Norde W (2008) Biosens Bioelectron 24:552-557

37. Rebe Raz S, Bremer MGEG, Haasnoot W, Norde W (2009) Anal Chem 81:7743-7749

38. Maragos CM (2009) Anal Bioanal Chem 395:1205-1213

39. Natarajan S, Katsamba PS, Miles A, Eckman J, Papalia GA, Rich RL, Gale BK, Myszka DG (2008) Anal Biochem 373:141-146

40. Zachariasova M, Hajslova J, Kostelanska M, Poustka J, Krplova A, Cuhra P, Hochel I (2008) Anal Chim Acta 625:77-86

41. Burmistrova NA, Goryacheva IY, Basova EY, Franki A-S, Elewaut D, Van Beneden K, Deforce D, Van Peteghem C, De Saeger S (2009) Anal Bioanal Chem 395:1301-1307

42. Tangni EK, Motte JC, Callebaut A, Pussemier L (2010) J Agric Food Chem 58:12625-12633 